\title{
Memorias dolorosas, memorias del dolor: reflexiones y debates mapuche sobre la restitución de restos humanos mapuche-tehuelche en la Patagonia argentina \\ Painful memories, memories of pain: mapuche's reflections and debates on the return of human remains mapuche-tehuelche in Patagonia argentina
}

\author{
Carolina Crespo ${ }^{1,2,3}$
}

Solo el saber sobre el acontecimiento y sobre el contexto del registro permitirá restituir a esas imágenes su violencia escondida, reconocer la dimensión de su fuera de campo. Sylvie Lindeperg, en Didi-Huberman, 2005

\begin{abstract}
Resumen
Desde el año 2013 el gobierno de la provincia de Chubut -Patagonia argentina-impulsó varias restituciones de restos humanos indígenas en las que participaron numerosas comunidades mapuche y mapuche-tehuelche de la provincia; entre ellas, algunas de la Comarca Andina del Paralelo $42^{\circ}-$ noroeste de Chubut y sudoeste de Río Negro-. Este artículo examina la dinámica y reflexiones que este proceso fue generando entre los mapuche de esta región comarcal. Dinámicas y reflexiones que fueron encuadradas en clave de "memorias dolorosas" en el marco de históricos reclamos territoriales y de procesos de reafirmación de subjetividades y derechos indígenas. El propósito del trabajo es mostrar cómo en estos procesos, "restos" que parecían formar parte de un patrimonio inerte fueron vitalmente refigurados, iluminando la historicidad y las tensiones de la geografía física y social del espacio y las violencias, continuidades e interrupciones que la han constituido. Para ello analiza el desplazamiento producido desde la noción de "restos humanos indígenas" como "objeto patrimonial" a "memorias dolorosas y del dolor"; examina las nociones que esas "memorias del dolor" propiciaron para repensar experiencias indígenas, y describe los vínculos y la construcción de lo "común" que se pusieron en juego en el marco de ciertas tensiones emergentes.
\end{abstract}

Palabras claves: restitución de restos humanos indígenas, memorias dolorosas, conceptualización, vínculos, Comarca Andina Paralelo $42^{\circ}$.

\begin{abstract}
Since 2013 the government of Chubut province, Patagonia Argentina, prompted several restitutions of indigenous human remains in which many Mapuche and Mapuche-tehuelche communities of this province participated, including some of the Andean Region of Parallel $42^{\circ}$-Chubut northwest and southwest of Río Negro. This article examines the dynamics and reflections that this process was generating among Mapuche of this local region. Dynamics and reflections that were framed like painful memories in the context of historical land claims and reaffirmation processes of subjectivities and indigenous rights. The purpose of this paper is to show how in these processes, "remains" that seemed part of an inert heritage were vitally refigured, illuminating the historicity and tensions of physical and social geography of space and the violence, continuities and disruptions that have formed it. It analyzes the displacement produced from the notion of "indigenous human remains" as "heritage object" to "painful memories and of pain", examines the concepts from which these "painful memories" allowed rethink indigenous experiences and describes the links and the construction of the "common" that put into play in the context of certain emerging tensions.
\end{abstract}

Keywords: restitution of indigenous human remains, painful memories, conceptualization, links, Andean Region Parallel $42^{\circ}$.

Recibido: 9 octubre 2016. Aceptado: 28 agosto 2017

1 CONICET: Consejo Nacional de Investigaciones Científicas y Técnicas, Ciudad Autónoma de Buenos Aires, Argentina. Email: info@conicet.gov.ar

2 INAPL: Instituto Nacional de Antropología y Pensamiento Latinoamericano, Ciudad Autónoma de Buenos Aires, Argentina. Email: leonor.acuna@inapl.gob.ar

3 Universidad de Buenos Aires, Ciudad Autónoma de Buenos Aires, Argentina. Email: correouba@rec.uba.ar 
Desde la reapertura democrática en Argentina, el paulatino incremento de demandas por la restitución de restos humanos indígenas ha traído aparejado la revisión retrospectiva y prospectiva -en cada instancia y desde cada contexto de discusión: indígena, científico, institucional, etcétera- de las políticas públicas mantenidas con los pueblos originarios y aquello que el Estado en sus distintos niveles y/o la ciencia han incorporado de estos pueblos bajo la categoría de "patrimonio", "objeto" de colección, exhibición, discurso o conocimiento. ${ }^{4}$ En el marco de esta revisión, el gobierno de la provincia de Chubut -Patagonia argentina- impulsó entre los años 2013 y 2015 varias restituciones de restos humanos indígenas en esta provincia, en las que participaron en calidad de invitadas o como directas reclamantes, numerosas comunidades mapuche y mapuchetehuelche.

Entre las comunidades que participaron en estas restituciones se encuentran algunas de la Comarca Andina del Paralelo $42^{\circ}$, región cordillerana que abarca cuatro localidades del noroeste de la provincia de Chubut -Lago Puelo, Epuyén, El Hoyo, El Maitén- y la localidad de El Bolsón en el sudoeste de la provincia de Río Negro. Desde el año 2004 investigo sobre procesos de patrimonialización y construcción de memorias con varias de estas comunidades mapuche que están llevando adelante una serie de reclamos de derechos, en especial -aunque no exclusivamente- de derechos territoriales. Como parte de esta línea de preocupación, me interesa en este artículo examinar la dinámica e implicancias que generaron estas restituciones de restos humanos entre los mapuche de esta región. En la literatura científica, la mayor parte de los trabajos sobre esta problemática se centraron en recorrer los itinerarios seguidos por la restitución de ciertos restos humanos indígenas identificados. Siguiendo siempre un caso específico de restitución, se focalizaron en los procesos de reclamo y/o en sus efectos. Describieron las discusiones que despertaron al interior de los museos, los debates y posiciones adoptadas por diversos académicos, y las interrelaciones y proyectos de reclamo de comunidades y/o pueblos indígenas en Argentina a la luz de procesos de construcción y disputa por

4 Estas discusiones siguen abiertas y muestran las heterogeneidades y tensiones presentes al interior de estos sectores. la hegemonía (Di Fini, 2001; Curtoni y Chaparro, 2007, 2011; Lazzari, 2008; Arenas, 2011; Endere, 2011; Oldani et al., 2011; Rodríguez, 2011; Jofre, 2012; entre otros). Los análisis fueron muy valiosos y enriquecedores, pues revisaron críticamente prácticas institucionales estatales y/o de nuestra disciplina. Paralelamente, examinaron estas prácticas en su articulación con procesos de demanda indígena. En esta oportunidad, y a modo de contribuir con este debate, me propongo presentar no tanto un análisis del proceso de restitución de un caso en particular, sino un examen sobre la dinámica, debates, tensiones y reflexiones que este fenómeno fue poniendo en escena entre los mapuche de esta región comarcal. Dinámicas y reflexiones que fueron encuadradas por ellos en clave de "memorias dolorosas" en el marco de históricos reclamos territoriales y de procesos de reafirmación de subjetividades y derechos indígenas.

Mi propósito es mostrar cómo en estos procesos, "restos" que parecían formar parte de un patrimonio inerte fueron vitalmente refigurados (Stoler, 2008) por estas comunidades. Más allá de modalidades de "reparación y justicia", devinieron en potenciales semánticos abiertos y dispositivos de transmisión de experiencias a generaciones contemporáneas y posteriores. Apuntaron a instalar sensibilidades; organizar miradas, lenguajes y tópicos de reflexión; trazar vínculos políticos y configurar espacios-tiempos de encuentros de trayectorias, conexiones y relacionamiento intraétnico e interétnico dentro de históricos procesos de lucha territoriales. Lo que sigue a continuación se detiene entonces a profundizar sobre ciertas miradas y prácticas que estos mapuche fueron manifestando en estos procesos. A través de una perspectiva centrada en la antropología social, que combina entrevistas, intercambios comunicativos informales, relatos difundidos en medios de comunicación escritos y radiales ${ }^{5}$ y observación-

5 En esta zona, la radio tiene un papel central como medio de comunicación, y las reflexiones emergentes sobre la temática fueron especialmente ricas en este ámbito. Más allá de relevar distintos programas que dieron lugar a la difusión de estos eventos en radio ALAS y en radio Nacional El Bolsón, recupero especialmente aquí el programa semanal conducido por tres mujeres mapuche de esta localidad -Elisa Ose, Soraya Guitart y Mirta Nancunao-denominado Zungu kelu ta kuyen: es la luna la que habla. Este programa incluía un personaje 
participante, examino en una primera instancia el desplazamiento producido entre los mapuche de esta región desde la noción de "restos humanos indígenas" como "objeto patrimonial" a "memorias dolorosas y del dolor". Luego analizo las nociones que esas "memorias dolorosas" propiciaron entre ellos para repensar experiencias indígenas. Finalmente, reflexiono sobre los vínculos y la construcción de "lo común" que pusieron en juego en el marco de ciertas tensiones y conflictos emergentes.

\section{Memorias dolorosas, memorias del dolor: abrir los tiempos, sensibilizar los cuerpos}

Entre los años 2013 y 2015, varias comunidades mapuche de la Comarca Andina participaron de restituciones de restos humanos indígenas llevadas adelante por la provincia de Chubut. Según el ex secretario de Cultura provincial, institución que tuvo un papel fundamental en la decisión, estas restituciones fueron realizadas en el marco de una política provincial de promoción de los derechos humanos -de "Memoria, Verdad y Justicia"- que buscaba "lograr una reparación histórica" y restituir el derecho a enterrar los cuerpos muertos de acuerdo a las propias creencias. ${ }^{6}$ Pero también, según él, estas restituciones se explicarían como producto del "avance de la democracia [...], del empoderamiento a través de la lucha y de la resistencia de las comunidades de pueblos originarios, de las decisiones politicas de la clase dirigente [...] [y de] un cambio de paradigma en muchos antropólogos" (Entrevista al ex secretario de Cultura, 2016).

La primera restitución en la que participaron miembros de las comunidades de la Comarca Andina de Chubut tuvo lugar en la localidad de Gaiman en el año 2013. En 2006, una pobladora de Gaiman había encontrado restos humanos en la cima del cerro Loma Torta en esta localidad. La Secretaría de Cul-

ficticio, "Doña Cata”, protagonizado por Mirta Nancunao, werken - mensajera- de la comunidad mapuche Las Huaytekas. El personaje "Doña Cata” representaba a una vecina de El Bolsón a la que solían entrevistar en el programa para conversar sobre problemáticas indígenas.

6 Estas políticas se desarrollaron durante la gestión del gobierno de Chubut que transcurrió desde 2011 hasta fines de 2015. tura provincial solicitó a científicos pertenecientes al Centro Nacional Patagónico (CENPAT) de Chubut -dependiente del Consejo Nacional de Investigaciones Científicas y Técnicas (CONICET) - "rescatar, preservar y analizar" los restos encontrados. Los arqueólogos iniciaron una serie de "tareas de rescate" previa consulta a la comunidad mapuchetehuelche Ceferino Namuncurá-Valentín Sayhueque y a autoridades de Gaiman. Las tareas contaron con la aprobación y participación de miembros de esta comunidad y de quien había encontrado estos restos óseos. En ese espacio, se hallaron un total de 13 esqueletos de distintas edades y sexos que -según los estudios realizados- habían sido enterrados hace alrededor de 300 o 350 años AP. En 2010, la comunidad mapuche-tehuelche Ceferino NamuncuráValentín Sayhueque solicita a la Secretaría de Cultura de la provincia de Chubut sepultar nuevamente estos restos humanos indígenas donde habían sido hallados. En 2013, el gobernador de la provincia y el secretario de Cultura provincial -en el marco de la Ley nacional 25.517/01 de restitución de restos humanos indígenas y de su Decreto Reglamentario 701 promulgado en el año 2010- devolvía esos 13 cuerpos a dicha comunidad en un acto que definieron como parte de un derecho humano y de dignidad y una forma de encuentro luego de historias de desencuentros (http://www.elpatagonico.com/hoyse-realizo-la-restitucion-restos-oseos-una-comunidad-aborigen-n690171).

La segunda restitución a la que fueron invitadas las comunidades mapuche de la Comarca Andina de la provincia de Chubut fue en diciembre de 2014. Se trató de la restitución complementaria de restos del cacique Inakayal junto con la restitución de su mujer -cuyo nombre se desconoce- y de Margarita Foyel -hija del cacique Foyel y sobrina del cacique Inakayal- en la localidad de Tecka. El cacique Inakayal, el cacique Foyel y el cacique Sayhueque dominaban un extenso territorio en el norte de la Patagonia, denominado "País de las Manzanas". Finalizada la "Conquista del Desierto", 7 en 1884, los

7 Se denominó eufemísticamente bajo este nombre a las campañas militares llevabas a cabo a fines de siglo XIX sobre el territorio indígena en la Patagonia Argentina. Estas campańas tuvieron como resultado el exterminio de gran cantidad de población indígena, la apropiación del territorio y sus recursos por el Estado nacional y el 
caciques y sus familias fueron tomados prisioneros y trasladados a la isla Martín García. En 1886, a pedido del perito Francisco Moreno, director del Museo de La Plata, estos caciques y sus familias o allegados fueron llevados a dicha institución. Allí se los dispuso a trabajar $^{8}$ mientras fueron estudiados por científicos. Con excepción de Sayhueque y Foyel que habían sido liberados, el resto muere en $1887-1888^{\circ}$ en el museo y sus restos pasan a ser diseccionados para su estudio, constituidos como patrimonio nacional, y exhibidos sus esqueletos durante muchos años en las vitrinas de sus salas (Podgorny y Politis, 1990; Podgorny, 2000; Di Fini, 2001; GUIAS, 2010; Ametrano, 2015; entre otros).

La primera restitución de Inakayal había sido efectuada en el año 1994 (Miotti, 1994; Politis, 1994; Di Fini, 2001; Endere, 2011; Oldani et al., 2011; Caviglia, 2012; Ametrano, 2015). En esa oportunidad se habían restituido solo los restos óseos del cacique. En el año 2006, se hace pública la permanencia de algunos de sus restos blandos en el museo. La Asociación Civil Cacique Inakayal de Tecka y la Secretaría de Cultura de Chubut solicitan al Museo de la Plata la restitución complementaria de Inakayal. En el ańo 2014 se difunde a varias comunidades mapuche-tehuelche de la provincia de Chubut, la existencia de restos de otros familiares de Inakayal -su mujer y Margarita Foyel- que estaban en

sometimiento de aquellos indígenas que quedaron vivos.

8 Las mujeres tejían y los hombres realizaban tareas de maestranza. Según Ten Kate, "las mujeres enriquecerían las colecciones etnográficas con sus trabajos de tejidos, al mismo tiempo que se podría estudiar sus costumbres" (Ten Kate, 1904, en Endere, 2011).

9 Margarita y la mujer de Inakayal mueren en 1887. Poco se sabe acerca de estas dos mujeres. Se cree que la muerte de la primera a los 33 ańos fue producto de una afección pulmonar. Sobre su permanencia en el museo, quedaron algunos registros contradictorios. Estos últimos la describen con un carácter suave, tímido, indiferente pero, a la par, sostienen que era muy comunicativa. La califican como una mujer alegre, pero destacan su rostro triste. Además, plantean que era trabajadora e hilaba en el museo durante todo el día. Por el contrario, sobre Inakayal hay más registros e incluso varios escritos actuales sobre su vida y muerte (GUIAS, 2010; Endere, 2011, entre otros). Algunos señalan que murió en el museo en el año 1887; otros, en 1888. Las razones de su fallecimiento siguen abiertas y en discusión. el museo. Frente a ello, se suman al reclamo otras comunidades mapuche de Chubut y solicitan tanto los cuerpos de esos familiares como los objetos etnográficos y arqueológicos asociados (entrevista al ex secretario de Cultura, 2016). ${ }^{10}$ El gobernador de Chubut junto con autoridades del Museo de la Plata, del Instituto Nacional de Asuntos Indígenas (INAI), de la Dirección de Asuntos Indígenas de Chubut, la Secretaría de Cultura y Subsecretaría de Derechos Humanos de esta misma provincia y el Grupo Universitario de Investigación en Antropología Social (GUIAS) ${ }^{11}$ participaron en este evento. Los "restos" devueltos en esta oportunidad incluían el poncho que Inakayal había regalado ${ }^{12}$ al perito, su cuero cabelludo y una oreja; el esqueleto de las dos mujeres, las máscaras mortuorias, orejas, cabelleras $\mathrm{y}$ tres cerebros sin identificar pertenecientes a estos indígenas. Según el ex secretario de Cultura, la idea era entregar la totalidad de aquello que se había encontrado en el museo de cada sujeto, y no algunas partes, como había ocurrido con la primera restitución de Inakayal. De ahí que se reunieron varias comunidades mapuche-tehuelche de Chubut, las autoridades del Museo de La Plata, el gobierno de la provincia y el grupo GUIAS para firmar un Acta Acuerdo Compromiso. En este acta, las comunidades indígenas firmantes consentían que el Museo de la Plata extrajera una muestra de esos cerebros con el fin de intentar identificarlos a través de estudios de ADN. En paralelo, las autoridades de la Facultad de Ciencias Naturales de la Universidad de La Plata

10 En 2014 se suman al pedido de reclamo de la Asociación Civil Cacique Inakayal, las comunidades que integran el Consejo de Comunidades Mapuche-Tehuelche de Chubut (costa y valle) y la Comunidad Nahuelpan de Tecka con el apoyo del gobierno de la provincia del Chubut (Ametrano, 2015).

11 El colectivo GUIAS es una organización autoconvocada de la Facultad de Ciencias Naturales y Museo de la Universidad de La Plata que, desde el año 2006, trabaja en la identificación de restos existentes en el Museo de la Plata para su posterior restitución. Según sus integrantes, el objetivo de este colectivo es "atender los reclamos realizados por los Pueblos Originarios de no exhibición y restitución a sus comunidades de todos los restos humanos que forman parte de 'colecciones arqueológicas', en especial los $10 \mathrm{mil}$ restos humanos que se encuentran en el Museo de La Plata" (http://colectivoguias.blogspot.com.ar/)

12 Algunos mapuche de la Comarca pusieron en duda que fuese un regalo. 
y de este mismo museo se comprometían a restituir todos los restos que poseían de estos sujetos a los reclamantes, incluidos aquellos cerebros que estaban sin identificar. ${ }^{13}$ En este caso, el gobernador -en nombre del Estado provincial- pidió "perdón por los crímenes que el Estado cometió [...] durante la llamada Conquista del Desierto" ${ }^{14}$ y la directora del Museo de La Plata destacó que "cada restitución constituye la devolución de la condición de personas y una contribución a la construcción de una sociedad nueva, rica en diversidad cultural" 15 .

La tercera restitución tuvo lugar en el año 2015. La Secretaría de Cultura de la provincia de Chubut "impulsa la puesta a disposición de los restos humanos de Margarita Foyel y su mascarilla mortuoria a favor de las comunidades de pueblos originarios de Chubut para que éstas los entreguen efectivamente a la comunidad mapuche Las Huaytekas" (Resolución 230, 18.11.2015) de la localidad de El Bolsón (provincia de Río Negro) en la Comarca Andina. Los restos de Margarita Foyel "habían quedado en custodia de las comunidades de pueblos mapuchetehuelche de Chubut" en Tecka en diciembre de 2014, mientras se lograra individualizar los cerebros y "se decidiera respecto de su destino final, atento

13 Las antiguas modalidades de conservación en formol en combinación con el tiempo transcurrido impidieron identificar los cerebros. El museo había solicitado consentimiento para poder individualizarlos mediante la extracción de una muestra en el año 2006, pero no habían obtenido resultado alguno (Ametrano, 2015). El 1 de septiembre de 2014 firman el "Acta Acuerdo Compromiso". En ésta se establece la transferencia en custodia a las comunidades de los tres cerebros hasta su posible identificación. También se especifica que, en caso de que el Museo lograra identificar a quién pertenecía cada cerebro, las comunidades se comprometían a restituirlos a quien corresponda. Además, se establece que las autoridades de la provincia se comprometían a colaborar, gestionar y facilitar todos los recursos para que en el transcurso de ese año se materializara lo acordado en el Acta (Acta Acuerdo Compromiso 1.09.2014). Como se expondrá más adelante, los estudios de ADN realizados en esta oportunidad no permitieron finalmente identificar los cerebros.

14 El Patagónico http://www.elpatagonico.net/nota/264528buzzi-pidio-perdon-por-los-crimenes-de-la-conquista-deldesierto/ Consultado el 15.12.2014.

15 http://www.diagonales.com/sociedad/217070-elmuseo-de-la-plata-restituyo-los-restos-de-un-cacique. html. 9/12/2014 Consultado el 15.12.2014. a que la comunidad mapuche de las Huaytekas había reclamado [su] restitución" (Resolución 230, 18.11.2015).

Cada una de estas restituciones tuvo características diferentes, tanto respecto a quiénes intervinieron, organizaron y/o protagonizaron los eventos como a la forma que adoptaron y la historia de los sujetos que eran restituidos. Las dos primeras restituciones fueron organizadas por instituciones provinciales $y$ acompañadas por el Instituto Nacional de Asuntos Indígenas así como por autoridades del CENPAT, la primera; y por el Museo de La Plata y el colectivo GUIAS, en el caso de la segunda. A pesar de la relevancia otorgada al hecho de que el Estado provincial reconozca su responsabilidad y disculpas por los crímenes cometidos durante la "Conquista al Desierto", muchos mapuche de la Comarca Andina fueron críticos del carácter político que tuvieron las restituciones y de algunas "exigencias" no deseadas que incluso no fueron asumidas por ciertas comunidades durante el evento: sacarse fotos con los funcionarios de la provincia, hablar en público, etcétera. Por el contrario, en la restitución de Margarita Foyel, fueron las comunidades mapuche las que tomaron mayor decisión respecto a la organización y participación de la misma. Asimismo, la historia de los "restos" restituidos en Gaiman difiere de la historia de aquellos que el Museo de La Plata ha tenido y continúa teniendo en su interior, por la violencia y racialización que acompañó durante muchos años la conformación de esta colección museal, su estudio y exposición. Como ha sido documentado por varios autores, una parte importante de estas colecciones se conformó a partir de esqueletos saqueados de las tumbas en Patagonia que fueron donados a este museo -como es el caso de la colección de Estanislao Zeballos, abogado e intelectual orgánico del general Julio Argentino Roca, quien dirigió la "Conquista del Desierto"-, o bien, de exhumaciones de tumbas, tal como lo menciona haber hecho el propio Francisco Moreno, primer director de esta institución. Otros esqueletos -entre ellos, Inakayal, su mujer y Margarita Foyel- pertenecían a indígenas que, como ya se señaló, fueron trasladados luego de las campañas militares de fines de siglo XIX a esa institución como personal de servicio y objeto de estudio de la ciencia y, con posterioridad a su muerte, agregados y exhibidos como parte del acervo patrimonial de la 
misma (Podgorny y Politis, 1990; Di Fini, 2001) y estudiados sus huesos y cerebros para "documentar" una supuesta inferioridad racial (Politis, 2000).

No obstante, y más allá de las diferencias reseñadas respecto a la historia de los cuerpos restituidos y a las restituciones, los mapuche de la Comarca Andina inscribieron todos estos "restos" que históricamente las agencias estatales y científicos concibieron como "objeto de estudio" y "colección patrimonial", como parte de sus "memorias dolorosas" y de genealogías, cuerpos e historias que no deben ser manipuladas. A lo largo de más de 10 años de trabajo en la zona, los mapuche con los que interactué han criticado directa o indirectamente cualquier tipo de remoción de restos humanos indígenas y de aquellos objetos que estuviesen enterrados con esos cuerpos. Sea a través de leyendas o de denuncias directas, me han manifestado recurrentemente acerca de la pertenencia indígena de esos cuerpos, su respeto hacia sus antepasados y/o el efecto peligroso e irreversible que puede producir el desentierro de los mismos por parte de un "extranjero" o un "blanco" (Crespo, 2008, 2012). ${ }^{16}$

...yo tengo un montón de antepasados y en algún tiempo, seré un antepasado de mis hijos y así.. [...] hay lugares donde hay entierros $y$ nadie en la casa [se refiere a casas de mapu-

16 Estos señalamientos solían aparecer tanto entre una mayoría mapuche de la región, que ha trazado relaciones de continuidad con quienes vivieron en períodos muy lejanos en el tiempo (Crespo, 2011), como entre una minoría con quienes interactué, entre los ańos 2004 y 2008, que en ese entonces establecía relaciones más ambivalentes y complejas - de continuidad y discontinuidad simultáneamente- con quienes vivieron en un pasado más lejano, previo a la "Conquista al Desierto". Esta minoría reconocía como sus antepasados a quienes vivieron en momentos históricos lejanos y establecía a través de ellos una continuidad en la ocupación territorial. En paralelo, señalaba cierta disyunción con ese pasado al definir a estos sujetos como "indios salvajes" en contraposición a ellos mismos que se concebían y clasificaban como "indígenas civilizados". Tal como lo analicé en otro trabajo, dicha ambivalencia exponía la internalización del relato y la práctica colonizadora y, en simultáneo, la confrontación con narrativas hegemónicas que ubican la ocupación de este espacio cordillerano en épocas recientes, a fines del siglo XIX. Para una mayor profundización sobre esto, véase Crespo (2008, 2012). che] se lleva un pedacito porque es como invadir un espacio que, o sea, hoy lo está ocupando alguien que se fue y sigue siendo su espacio (Entrevista a F, 2006)

Como sugiere este relato, conciben a los muertos no como un objeto inerte del pasado, sino dentro de un marco interpretativo que los inscribe como ancestros, antepasados o antecesores que ocupan un espacio, poseen poder y acción sobre los sujetos en el presente e interactúan con quienes aún permanecen vivos (Crespo, 2008, 2012). De ahí que las restituciones dieron lugar a debatir sobre experiencias de avasallamiento vividas con relación a su cosmovisión, sus cuerpos, sus vínculos, historias y espacios territoriales. Esto es, sobre experiencias de sufrimiento, crueldad y tristeza que viven e integran como parte de memorias de dolor indígenas. Memorias cargadas de una fuerte intensidad emocional $y$ afectiva que dieron lugar a sentimientos y recuerdos ambivalentes -aunque no contradictorios- entre los vivos: de tristeza y llanto por lo padecido, pero también de alegría y festejo por el regreso de los cuerpos a su espacio; de sometimiento y pérdida, pero también de lucha.

\section{"Estamos de fiesta pero con tristeza. Fue impac- tante ver cómo descuartizaron a nuestro lonko [cabecilla o cacique] los que hicieron esto pen- saban que iban a matarnos, pero acá estamos vivos", expresó Simón Nahuelpán, de la comu- nidad de descendientes directos de Inakayal ("Llegaron los restos de Inakayal a Tecka y comenzaron las ceremonias tehuelches ma- puches"). 9.12.2014. Disponible en: http:// www.telam.com.ar/notas/201412/88279- inakayal-a-tecka-restos-ceremonias-mapu- ches.html (Consultado el 15.12.2014)}

Las "memorias de dolor" y de experiencias de violencia colectiva han sido foco especial de atención dentro de los estudios que observaron a la memoria social como práctica política (Pollak, 2006; Jimeno, 2007; Das, 2008; Ortega, 2008 y 2011). En su mayoría, estos estudios analizaron la posibilidad de expresar recuerdos de violencia y su potencial para configurar subjetividades (Vich y Zavala, 2004; Pollak, 2006) y/o "comunidades afectivas" (Jime- 
no, 2007; Das, 2008). Los estudios se centraron en experiencias traumáticas directamente vividas por aquellos que las expresaban y/o cubrían bajo un manto de silencio. Por el contrario, los procesos de restitución de restos humanos indígenas pusieron en primer plano memorias de dolor de sujetos y períodos históricos no vividos por quienes las evocaban, ni difundidos por las instituciones hasta hace unos ańos atrás e, incluso, silenciados algunos en el interior del hogar de muchos indígenas. Memorias que, si bien como ellos mismos sostienen, a veces resultan difíciles de expresar y transmitir por su crueldad y el silenciamiento que las acompañó, justamente por ello consideran casi como un mandato la necesidad de ponerles palabras e imágenes para su transmisión y reflexión.

Sin lugar a duda, fueron las restituciones del lonko Inakayal, su mujer y Margarita Foyel las que generaron mayores repercusiones y debates entre los mapuche de la Comarca. La historia vivida por estos indígenas y la forma que siguió la restitución de estos cuerpos dieron lugar a gran cantidad de relatos difundidos en el marco de trawn -encuentros $^{-}$, rogativas y/o ceremonias de enterramiento, pero también en programas radiales y otros medios de comunicación en la esfera pública. Con el objeto de dar testimonio, legitimarlo y reconstruir esas trayectorias, algunos fueron narrados en tercera persona, evocando una narrativa histórica. Otros afloraron como parte de un "nosotros" dentro del género de contadas de "la gente de antes". Estos relatos interpelaron especialmente los silencios y lagunas existentes en la construcción y transmisión de la historia oficial, como aquellos devenidos en los propios hogares indígenas, producto de estos mismos discursos, censuras y políticas estatales establecidas hacia ellos. Además, apuntaron a contraponer negativamente las prácticas desarrolladas en otras épocas en el Museo de La Plata versus aquellas atribuidas positivamente a estos indígenas que habían sido recluidos. Denunciaron las relaciones de servidumbre entabladas con los mapuche-tehuelche por quienes conformaban el museo; manifestaron la crueldad con la que trataron sus cuerpos luego de su muerte; señalaron el ocultamiento de sus nombres bajo un número o letra con el que identificaron cada resto, criticaron la imposición de la cultura occidental y la legitimación del proceso de expropiación territorial operado sobre ellos. A la par, describieron a los indígenas que allí estaban como luchadores, aunque abatidos luego de la Conquista; como trabajadores y educados, pero tristes durante su permanencia en aquella institución.

En líneas generales, estas narrativas se acompañaron de manera recurrente de una fuerte intensidad afectivo-emocional perceptible a través del contenido, adjetivos y nombres otorgados a cada situación descripta, y de las formas expresadas dentro y fuera de las ceremonias de restitución y/o entierro. Los relatos emergían cubiertos de adjetivos calificativos. Las voces se quebraban y mostraban acentuaciones de enojo en el discurrir narrativo. Y, particularmente durante las ceremonias, emergió recurrentemente el llanto, el silencio, las pausas.

Si, lloraban. [pausa] Viajaban ñanas, chicas,
hombres, todo. Pero era asi, lo sentís de cora-
zón o no lo sentís. Desde el corazón lo siente
uno. Como que eso, es como que te despierta
la mentalidad. Historia de atrás, lo que su-
frieron todo ellos. Y por eso te da esos bajones
de sentimiento. Porque vos no digas, no, yo no
era así... Casi la mayoría, los peñis [herma-
nos] casi todos lloran. Ahí, en Tecka, llora-
ban todos. [pausa] ;Uh! ¡la abuela, las ñañas
chicas lloraban todas! [énfasis] (Entrevista a
V, 2015).

En sus narrativas suelen hablar de "dolor", "sufrimiento", "tristeza, "llanto", "bronca", "impotencia", "alivio", "felicidad". Emociones todas ellas que remiten y entraman, un "sentimiento colectivo" más que individual -según me comentaba un mapuche- y que contienen un contenido moral y un potencial como instrumento político. Pues en el mismo acto, tanto en los relatos difundidos como en el evento de enterramiento o deposición de los cuerpos y objetos del mismo, fueron denunciando y restituyendo, en paralelo, no solo cuerpos individuales sino -como veremos- cuerpos políticos, tiempos y trayectorias comunes.

Entre los relatos que "testimonian" la violencia infligida se encuentran los propios cuerpos. Cuerpos que se han configurado como superficies sobre los 
que se "escribieron" y leen, para muchos mapuche, la violencia del Estado y de la propia institución museal y la crueldad moral que acompańó y operó en el proceso de su colección, su estudio y patrimonialización. Así, entre las experiencias más dolorosas que suelen relatar quienes están vivos y participan de estos eventos, se encuentra el impacto, legibilidad y poder que generan las imágenes - "ver", "palpar" y no solo "saber"- acerca de cómo esos esqueletos fueron escritos, marcados, diseccionados y unidos con alambre.

Él [Perito Moreno] coleccionaba los cráneos [énfasis] de nuestra gente, orejas [énfasis] de nuestra gente, los huesos [énfasis] de nuestra gente. Él armaba [énfasis] los esqueletos, ;los mandaba a descuartizar! ;a descuartizar lamgen! [énfasis] [Tono de indignación] ¿Sabe lo que significa eso? Nadie [énfasis] hace eso, ni, ni en otras guerras yo he tenido noticias de que hayan pasado cosas... que estando presos y que después se muere y después descuarticen, después le saquen la carne, después... este chico [énfasis] que se criaron en el museo lo tenian de funebrero y para descarnar a la gente [Tono triste] [...] ¡Es grave y es doloroso y es muy profundo lo que hay que resolver!... ("Doña Cata", personaje protagonizado por M de la comunidad Las Huaytekas, en el programa Zungu kelu ta kuyen, Radio Nacional El Bolsón, octubre de 2015).

Las imágenes de violencia inscriptas en los cuerpos adquirieron mayor fuerza entre los mapuche de la Comarca al articularse con dos experiencias. Por un lado, con la escucha en ańos recientes de relatos de algunos mayores que reunidos en trawn fueron animándose -en un contexto en el que era decible y escuchable- a contar experiencias extremas vividas y/o transmitidas durante la Conquista.

Y a mi me interesa esa... esa historia que casi nadie conoce que es la historia de nuestros antepasados, de cómo nuestra gente sufrió, de cómo nos mataron, de cómo nos llevaron a Buenos Aires, por lo que estaban contando y por lo que a mi me contaron también. Margarita y mucha gente más llevaron a Buenos Aires. Y allá murieron en un museo y los ponian en la vitrina para que se vean entre ellos mismos!, se vean entre los que se iban muriendo en el museo. Eso contaba la gente de antes. Y eso fue muy triste porque dicen que gente que vio, que [...] pero se iban de a pie a Buenos Aires. Los llevaban a unos de a caballo, a otros de a pie. Pero cuenta mi abuelo, no sé si estaba él o el papá de él, no sé, pero me contaba que dice que a los hombres los llevaban acá atados en los tobillos, ¿vio?, con cadena y a los que no iban con cadena dice que los cortaban el tendón acá para que no se escapen. $Y$ después, otra, iban mujeres que iban a tener nenitos y los tenian en el camino y dice que la gente que los llevaba, la gente mala ésa, del ejército, dice que cuando tenian su nene las lamgen, lo agarraban de las patitas, ¿vio?, y le daban contra las piedras, los mataban y los tiraban. Asi que no se quedaban con sus chiquitos. Asi que asi llevaban ellas cuando estaban por tener a su nene, iban acostadas en el caballo, las colgaban en los caballos porque ya no podian aguantar.. las que aguantaban porque algunas morian en el camino nomás [combina en el relato un tono triste y enojado] ("Doña Cata”, personaje protagonizado por M en el programa Zungu kelu ta kuyen, Radio Nacional El Bolsón, octubre de 2015).

Por otra parte, esas memorias de violencia adquirieron fuerza al combinarse con una situación inacabada en lo que respecta a reclamos de derechos territoriales que se conectan con aquellas historias de conquista y de estos cuerpos restituidos; pero también en lo que respecta a ciertas situaciones ocurridas en la restitución complementaria de Inakayal, de su mujer y de Margarita Foyel que serán expuestas en lo que sigue.

Las restituciones, particularmente la de Margarita Foyel, fueron haciendo públicas historias y experiencias que habían quedado guardadas dentro del espacio de instituciones como el museo. Su reflexión y conocimiento fueron abriendo la posibilidad de repensar procesos, prácticas y saberes compartidos desde una clave emocional, vívida y política. Estas experiencias y recuerdos, así como las definiciones, nombres y vínculos entablados -como se expondrá-, no solo documentaron una historia sino su conexión con un contexto más reciente de experiencias de violencia, alterización y subalternización no 
resueltas ni cerradas. Y es justamente esta conexión la que impulsó a que esos recuerdos se volvieran mandatos de discusión y transmisión tanto para generaciones contemporáneas al acto de recordar como principalmente para las venideras.

\section{Reflexiones sobre el dolor: abrir los ojos, nombrar experiencias}

Benjamin sostenía que aquello que las historias transmitían de uno a otro era el consejo o la sabiduría. Ese consejo no tenía que ver tanto con una respuesta sino más bien con una sugerencia sobre la continuidad de una historia en curso y la forma de obtener ese consejo era tener antes la capacidad de contar esa historia (Benjamin, en Mc Cole, 1993).

Los procesos de restitución ocurridos en Chubut sacaron a la luz esa capacidad. En todas sus fases, desde las instancias de demanda hasta el momento incluso en que se realizaron las ceremonias y a posteriori, estas restituciones dieron lugar a la formulación de preguntas, conceptos y reflexiones dentro de una cadena de discusiones entre quienes ya venían preguntándose sobre la propia historia pasada y presente, pero que, en muchos casos, desconocían algunos eventos. Preguntas y conceptos que refieren tanto a las relaciones de poder mantenidas sobre los pueblos indígenas como a las prácticas de silencios que, como consecuencia de ello, fueron instalándose en hogares indígenas con relación a ciertas temáticas, experiencias y saberes. Entre estos conceptos bajo los cuales nombrar y dar sentido a estas experiencias aparecieron con fuerza entre varios mapuche de la Comarca las nociones de "genocidio" y, complementariamente, de "dignificación a los propios ancestros como pueblo". "La colección antropológica como lo que se encuentra o se encontraba en el Museo de La Plata se fue formando en el marco del genocidio del Estado contra los pueblos originarios" (L, en el programa Zungu kelu ta kuyen, Radio Nacional El Bolsón, octubre de 2015).

El concepto de "genocidio" ha sido utilizado por el colectivo GUIAS en sus denuncias sobre el accionar de la ciencia antropológica y del Museo de la Plata durante fines del siglo XIX y gran parte del siglo XX. Ha sido invocado por los aché en el proceso de res- titución de Damiana Kryygi (Arenas, 2011). ${ }^{17}$ También ha integrado el discurso formulado por algunos funcionarios de la provincia de Chubut durante las restituciones desarrolladas en estos últimos tres años. Pero si bien ya utilizado por otros actores sociales, el acto de renombrar procesos y políticas habilita a quien lo hace, como sugiere Ortega (2008), a adueñarse de nociones que restituyen un sentido de la ausencia y de lo testimoniable, dando lugar a la formulación de otras preguntas sobre lo sucedido. ${ }^{18}$

A diferencia de las acepciones transmitidas por los funcionarios provinciales, la noción de "genocidio" en los relatos mapuche involucró algo más que una palabra para reflexionar sobre un evento como la "Conquista del Desierto" o un momento sito en el pasado. Comprendió una "perspectiva” para repensar toda una serie de políticas de Estado mantenidas hacia ellos, entre las cuales se encuentran aquellas relativas al campo patrimonial. En distintas instancias, desde el proceso de reclamo hasta los eventos de restitución, muchos mapuche de esta región comarcal documentaron y discutieron las implicancias que ha tenido el proyecto político de larga data $y$ duración vinculado con la expansión capitalista. Destacaron los despojos y exterminios que este proyecto supuso, la imposición de la soberanía estatal y occidental sobre el territorio, los recursos y los sujetos, y sus consecuentes regímenes de saber, violencia $y$ poder que, aun con variantes, consideran que no están clausurados: "El genocidio sigue existiendo, la tortura sigue existiendo, la persecución politica sigue existiendo" (I, en el programa Zungu kelu ta kuyen, Radio Nacional El Bolsón, octubre 2015). Regímenes que implicaron que sujetos y saberes indígenas se convirtieran en aquel entonces en "residuos" del pasado, propiedad del Estado, "patrimonio" museístico y objeto de investigación de la ciencia bajo un discurso nacionalista y racializante. Regímenes

17 Según Arenas (2011), los aché comprendieron las prácticas cometidas contra Damiana como violación de los derechos humanos y parte de un genocidio perpetrado contra los pueblos indígenas.

18 Entre esas preguntas y sospechas, emergió quizás la más básica: aquella que se interrogaba sobre la autenticidad del nombre de Margarita Foyel frente a prácticas de imposición de nombres en español y sobre quiénes eran los sujetos/cuerpos que todavía quedaban "presos" -retomando una categoría nativa- en el museo. 
de alterización y subalternización que, ellos señalan, se continúan bajo otros formatos y discursos en el presente; como por ejemplo en la histórica ausencia de regularización dominial del territorio reclamado.

Muchas comunidades en la Comarca están reclamando desde hace varios ańos su espacio territorial. Varias incluso lo están haciendo en el ámbito de la justicia. En recurrentes relatos y a través de la devolución de los cuerpos a su espacio expropiado, como el caso de Margarita Foyel, las restituciones han evocado la existencia de territorios arrebatados aún en litigio, y reafirmado la lucha por ellos. Algunos reclamos de restos humanos se han articulado con demandas territoriales de quienes solicitaron la restitución de los cuerpos; o bien, como en la localidad de Gaiman, el espacio donde hallaron los cuerpos indígenas restituidos fue cedido en el año 2012 a la comunidad Ceferino Namuncurá-Valentín Sayhueque en calidad de posesión comunitaria. De manera que las restituciones operaron, en sus palabras y en la de los funcionarios provinciales, "dignificando" "a los ancestros", a quienes -como diría Didi Huberman (2015)- pueden "cerrar sus ojos" y organizar su entierro para devolverles su "libertad" y dignidad de ser humano, enterrándolos o depositándolos en su espacio. Pero por otra parte, operaron para los mapuche de la Comarca, "dignificando a un pueblo" y "una lucha por derechos", lo que trasciende la visión de los agentes estatales.

En la medida en que lograron situarse frente a los muertos manteniendo los ojos abiertos sobre ellos -"estamos vivos" (M, 2015)- las restituciones se han tornado instancias en las que ha sido posible transmitir, aprender y corporizar en el presente y para el porvenir, la indignidad y el horror de los que pueden ser capaces ciertos sectores sociales.

\section{[A]hora que puedan traer por lo menos a Mar- garita otra vez al lugar de acá de donde la sa- caron, que llegue nuevamente a su territorio, pero para nosotros es sumamente importante porque eso significa que estamos vivos, ¿vio? Que tenemos fuerza y que la seguimos luchan- do y que vamos a seguir reclamando por nues- tra gente, por todos aquellos que los mataron, los asesinaron para quedarse con la tierra.}

Porque para eso era, porque nos sacaron toda la tierra y los mataron a todos los lonkos [...] Tenemos una herida grande [énfasis] todos nosotros, entonces bueno, eso por lo menos aliviana esa herida, ese dolor, pero eso no significa que la herida se va a cerrar, porque esta lucha va a seguir, tenemos que seguir luchando para que el Estado se haga cargo de todas estas cosas, porque el Estado [énfasis] fue el que mandó a matar a toda nuestra gente ("Dońa Cata", personaje protagonizado por $\mathrm{M}$ en el programa Zungu kelu ta kuyen, Radio Nacional El Bolsón, octubre 2015).

Entre las dignificaciones que habilitaron se encuentran la de conmemorar una memoria como pueblo, construir un futuro de memoria y una ética, y reafirmar y legitimar los reclamos sobre espacios demandados. Esto se hizo visible mediante el recuerdo vivo de un territorio indígena arrebatado a estos lonkos y familias cuyos cuerpos son restituidos, y exaltando la ejemplaridad de su lucha en defensa de lo propio: "eran lonkos, [énfasis] eran guerreros, lucharon por nuestro pueblo mapuche. Si fueron corridos hasta allá era porque pelearon hasta último momento [...]" (I, en el programa Zungu kelu ta kuyen, Radio Nacional El Bolsón, octubre de 2015). Pero también las restituciones contribuyeron a poner en escena, discutir y "dignificar" prácticas culturales y saberes considerados propios. En este terreno, dos hechos fueron destacados en las discusiones que llevaron adelante sobre la continuidad de formas de sometimiento, imposiciones hegemónicas y la necesidad de limitarlas. El primero refiere al debate gestado y no saldado entre los mapuche sobre el espacio donde deben permanecer los ancestros. Durante la primera restitución de los restos de Inakayal en Tecka, en 1994, se construyó un mausoleo para dejar el cuerpo. En este mausoleo fueron ubicados los restos de su segunda restitución, los de su mujer y los de Margarita -hasta ser finalmente enterrada-, así como los tres cerebros no identificados de estos indígenas. Muchos mapuche de la Comarca observaron en la construcción del mausoleo una continuación de formas de exotización y exhibición de los cuerpos indígenas propagadas por los museos. Lo rechazaron al concebirlo como una forma de aprisionamiento y cuestionaron la forma en que, según ellos, el gobier- 
no de Chubut procedió con los restos: "Manipulan parte de los restos de nuestra gente exhibiéndolos como trofeo [tono enojado y enfático]... ;Eso es lo que están haciendo!" "'Doña Cata", personaje protagonizado por $\mathrm{M}$ en el programa Zungu kelu ta kuyen, Radio Nacional El Bolsón, octubre 2015). Consideraron que se trató menos de un reconocimiento o reparación, como habían sido entendidas y enmarcadas estas restituciones por parte del Estado provincial, que de una estrategia de atracción turística a la localidad basada en la mercantilización de lo indígena. Objetaron el mausoleo como espacio conmemorativo, porque supone el (des)conocimiento de las propias prácticas mapuche y mapuche-tehuelche en torno al tratamiento de los cuerpos muertos; esto es, la elaboración de ceremonias indígenas de enterramiento. Dada las diferencias internas entre las distintas comunidades, los restos de Inakayal y su mujer quedaron finalmente en el mausoleo; sin embargo, el debate fue importante en la revisión de las relaciones inter e intraétnicas históricamente vividas.

El segundo hecho significativo que generó debates y retrasó el enterramiento del último cuerpo restituido -Margarita Foyel-, fue la falta de identificación de los cerebros. Los estudios de ADN no permitieron precisar su identidad y eso generó tensiones que fueron alimentando la revisión de las vivencias padecidas como pueblo indígena:

Nuestros lonkos están pidiendo la libertad porque siguen estando presos. La gente lloró [énfasis y pausa], las ñañas lloraron [pausa] de tristeza, sobre todo la ñaña que tiene que atender el cerebro, ¿vio?, que tiene que ir a medir el [pausa] formol, [énfasis] tiene que ir a medir la temperatura para que se mantengan los cerebros de Margarita, Inakayal y la esposa de Inakayal. Asi que está muy triste la lamgen que va a hacer ese trabajo. [pausa] Y por ahi nos hizo recordar todo lo que pasó en el Museo de La Plata, gente nuestra que tenía que descarnar a nuestra gente cada vez que se moría uno en el museo de la tribu de Inakayal, de Foyel... [pausa] y más o menos, no es que estén descarnando nada, pero siguen manteniendo eso para... no sé para qué [énfasis] cuando ya tendría que estar en tierra eso! [énfasis] Asi que fue triste, pero bueno, nos sirvió para darnos cuenta de lo doloroso que fue [...] nuestra historia [tono acongojado] (M, en el programa Zungu kelu ta kuyen, Radio Nacional El Bolsón, octubre de 2015).

[...] nosotros sentimos de carne propia ver como... pareciera que están sufriendo porque... están los cerebros abi en un frasco, que creo que a nadie se lo han hecho, a nadie... No sé si eso llegó a pasar con los 30 mil desaparecidos, con todo respeto, si hubieran encontrado restos en esas condiciones que nosotros los estamos encontrando... iEs grave! y jes doloroso y es muy profundo lo que hay que resolver! (M, en Radio Nacional El Bolsón, octubre 2015).

[...] es muy triste, es muy duro tener que estar dentro de ese mausoleo y ver los cerebros puestos en frasco de formol como una pieza científica, como un experimento de un científico, como una pieza de un museo... Tener que ver los restos de Inakayal sobre la tierra y no enterrados. Presos en el mausoleo y no en la tierra. Cuántos más dicen que están en el Museo de La Plata $y$ jen tantos museos! ¡de Argentina y del mundo! [resalta]. Porque lamentablemente nuestra gente era... era tomada como un bicho raro. Hacían sus colecciones de huesos, de cráneos, de cabellera, de orejas [pausa] y los desparramaban por el mundo, los vendian por el mundo... Entonces no es fácil pensar en toda esta situación (I, en el programa Zungu kelu ta kuyen, Radio Nacional El Bolsón, octubre 2015).

La tensión que esto implicó tuvo como contrapartida la reivindicación del conocimiento propio como saber legítimo para dirimir esta situación. Sin desestimar el saber científico, las comunidades de la Comarca Andina reivindicaron el conocimiento del machi, ${ }^{19}$ lo convocaron para definir a quién pertenecía cada cerebro y poder enterrar los restos de Margarita Foyel que permanecían en aquel mau-

19 Se trata de una figura que tiene un rol fundamental en términos de espiritualidad, cohesión, conocimiento y curación. Puede ser tanto un hombre como una mujer. 
soleo. ${ }^{20}$ En cierto sentido, su figura desafió el lugar de experto atribuido al académico, introduciendo la importancia de reconocer que figuras mapuche a las que históricamente se las ha diferenciado por su sabiduría y espiritualidad, como el/la machi, pueden y tienen legitimidad o autoridad para resolver situaciones de tensión vinculadas con la producción del saber. El reconocimiento de este saber traspasó incluso la esfera indígena, pues el entonces secretario de Cultura de la provincia de Chubut adhirió a aquello que el machi consideró respecto del cerebro de Margarita Foyel: "Después sí, a Margarita Foyel declaramos que los saberes de las comunidades eran suficiente para declarar identidad" (Entrevista a ex secretario de Cultura de Chubut, 2016).

En suma, la decisión de reclamar y enterrar los cuerpos humanos indígenas y particularmente de estos referentes indígenas -Inakayal, su mujer y Margarita Foyel- contenía -y sigue haciéndolo- una significación cultural y política en la que "genocidio" y "dignificación" fueron categorizando complementariamente experiencias y expectativas. Por una parte, se ha tratado de exhortar saberes, prácticas y actos performativos culturales indígenas a través de los cuales "invertir trayectorias negativas constitutivas de sus subjetividades en agencia política", tal como lo señala Rodríguez $(2011$, p. 2). Por otra, de seguir recordando la relación del mapuche con el territorio y despojos territoriales vigentes, así como legitimar su reclamo y mantener la llama de la lucha apelando a un apego histórico-político-afectivo.

\section{Anudar vínculos: reponer historias, saberes, experiencias y luchas}

Tal como lo sugiere Jimeno (2007) cuando analiza "memorias de dolor", en las restituciones se expresaron procesos sociales y mecanismos culturales por los que los sujetos conectan experiencias unos con otros, vivos y muertos, y los vuelven apropiables de forma colectiva, creando una comunidad que, más allá de las heterogeneidades -o, mejor aún, en esas

20 El machi realizó una ceremonia que permite "ver aquello que no se ve”. Mediante esta ceremonia determinó cuál de estos cerebros pertenecía a Margarita y permitió así habilitar su enterramiento con todos los restos completos. heterogeneidades- se pueda encontrar en trayectorias compartidas y proyectos y subjetividades políticas comunes.

Desde sus fases iniciales de reclamo hasta el entierro, las restituciones implicaron repensar quiénes "somos", aquello que liga, anuda, compone a un "nosotros" en relación a "otros" (Butler, 2006). En tal sentido, las restituciones se han asentado, en un proceso de revisión y reconstrucción de una "cadena de vínculos genealógicos" (Arenas, 2011) en la que estos sujetos restituidos -como se señaló anteriormente- son reconocidos como ancestros y sus historias como las "memorias de los antepasados". Ancestros con los que no necesariamente se tiene una descendencia biológica directa, sino que se viven y piensan como tales a partir del establecimiento de un fuerte vínculo afectivo basado en la edificación de una profundidad histórica, un origen común y una proyección política (Brow, 2000). ${ }^{21}$ Más aún cuando esta reconstrucción de memorias genealógicas acompaña y discute prácticas coloniales.

Asi que por eso un sentimiento, todo, muy feo. ¡Bah! son cosas muy verídicas, y uno lo siente como si fueron hermanos, un padre, una madre, pero uno los siente. [énfasis] Porque la misma sangre corre por todas las venas, ¿viste? (Entrevista a V, 2015).

La reconstrucción de estas genealogías y los lazos que se tejen con los antepasados se actualizan mediante la palabra y prácticas culturales que involucran otros lenguajes: rogativas, pewma (sueños), tayïl (cantos sagrados), etcétera. Estas prácticas y lenguajes se ponen en escena durante las ceremonias de restitución. Si usualmente, como sugieren Ramos (2010) y Stella (2016), estas prácticas culturales mapuche refuerzan lazos de reciprocidad entre vivos y ancestros y adquieren un fuerte contenido metacultural (Bauman, 2006) sobre el ser y hacer mapuche, en estos contextos de restituciones de antepasados,

21 Sobre este tema, véase Carsten (2007) y Ramos (2010), quienes analizan otros vínculos (sociales, materiales, afectivos y no exclusivamente biológicos) a través de los cuales se establecen lazos o formas de relacionamiento y parentescos donde no necesariamente existían, y sus implicancias políticas. 
estas performances se cargan de un plus de valor afectivo y político.

Con sus ceremonias, sus memorias abiertas, sus afectos y afecciones circulantes, las restituciones se configuran como espacios de construcción de vínculos y articulaciones entre mapuche vivos y con los ancestros muertos. Durante la restitución de Margarita Foyel, por ejemplo, miembros de la comunidad de Las Huaytekas señalaron que fueron los ancestros quienes indicaron cómo y dónde debía llevarse a cabo la restitución. ${ }^{22}$ Asimismo, varios mapuche interpretaron la lluvia que cayó a lo largo de los dos días de la ceremonia como expresión del llanto de Margarita por volver a su espacio. "Margarita venía llorando porque la llevaron libre y después la traen los huesos", decía Z. "La lluvia que está cayendo [...] son las lágrimas de nuestra hermana que vuelve con nosotros para siempre", pronunciaron otros. Estos encuentros colectivos con cuerpos e historias de antepasados se viven con gran intensidad y contienen algo del orden de lo corporalmente vívido e inefable. Durante la ceremonia de restitución de Inakayal, L me cuenta la emoción que le embargó llevar los cuerpos al mausoleo y, especialmente, ver los "restos":

Te hace, no sé... ¡Habia gente que no se soportaba! habia un hombre que parecia que no sé que le habia parecido... cuando sacaron todo eso ahí, le agarró, no sé... que empezó a gritar, que empezó a... después dijo que no se acordaba lo que le habia pasado... que corría... [hace un gesto corporal] una cosa, no sé [...] pero es como si fueras... porque te sentís algo de... en el cuerpo cuando la gente hablaba o cuando ya ves todo ahi, que se haya hecho realidad todo eso que tanto tiempo estaban luchando. ;Es fuerte! ¡Es fuerte! [énfasis] (L, com. pers., 2015).

En gran medida, la posibilidad de enlazar trayectorias comunes y afianzar vínculos o comunidades de pertenencia deviene de poner en discusión experiencias sufridas por quienes se conciben como ancestros. También de su lugar de expresión mediante

22 Según varios relataron, el lugar donde Margarita Foyel fue enterrada, le fue señalado a una mapuche en un pewma. instancias no verbales, en las que se pone en común un sentido y un lazo emocional que intentan reconstituir la herida sufrida como colectivo. El dolor habitable en el propio cuerpo transporta un contenido moral y un potencial para pensar y sentir procesos de alterización y subaltenización experimentados como pueblo. Potencial que se pronuncia con la selección de determinados lenguajes performativos y prácticas culturales que fueron acompañando las restituciones. Estos lenguajes performativos mapuche son importantes en varios sentidos. Por una parte, porque aun subsumidos a actos políticos del gobierno provincial -como en la restitución de Gaiman y de Inakayal y su mujer- o bien sin estarlo -como en la restitución de Margarita Foyel-, suponen reafirmar un lazo común en torno a un saber que es reconocido como compartido y "tradicional". Por otra, porque contribuyen a la identificación tanto con aquellos cuerpos muertos, en su calidad de "ancestros", como entre los vivos; pues van componiendo y recomponiendo lazos, memorias, afectos e historias para la acción política.

Estos vínculos genealógicos que se tejen en las restituciones entre muertos que no están totalmente muertos y los vivos reivindican y son indicativas de una presencia indígena activa, e importan porque ponen en escena y traen al presente junto a aquellas trágicas historias no saldadas, los derechos sobre un territorio que hasta hoy les ha sido negado.

Importante que él [Inakayal] se vino a descansar en su tierra, en su... en nativo donde nacieron, donde andaban ellos. Porque es un derecho que tiene uno, ¿vio? Porque es un derecho que uno dice "quiero estar en mi territorio" (Entrevista a V, 2015).

\section{Si, hay una comunidad, ahi hay un territorio que está recibiendo a Margarita y eso significa que nuestro pueblo sigue vivo, que al menos un poquito de nuestro territorio pudimos defender en nuestras manos (E, en Radio Nacional El Bolsón, septiembre de 2015).}

Aunque de manera dispar, cada una de estas restituciones motivó la lectura de procesos de subalternización y de pérdida a la luz de un proyecto de lucha 
y de organización. Las restituciones visibilizaron conflictos que pueden leerse en términos de residuo y/o como fuerza de resistencia, según el caso. El equilibrio entre ambas reflexiones y prácticas ha sido distinto en cada restitución. Particularmente la restitución de Margarita Foyel focalizó no solo en la pérdida o en la victimización pasiva del indígena, sino que apeló constantemente a la necesidad de organizarse en torno a la lucha de derechos, en especial la lucha territorial, para lo cual, la habilitación y rearticulación de vínculos y alianzas de distinto tenor, no solo entre indígenas sino también con no indígenas, ha sido clave. Los recuerdos que trazaron estas restituciones a través de distintos lenguajes -palabras, performances, cantos, imágenes, corporalidades, etcétera- en los que se denunciaron quiebres y/o límites impuestos por la dominación -e incluso con diferencias- se delimitaron agencias y demandas, han aportado a la constitución y/o alimentación de estos lazos. En efecto, los procesos de demanda y restitución de restos se conforman como un espacio de articulación entre mapuche y no mapuche, quienes conociéndose o no previamente, reconocen los procesos de sometimiento que han vivido los pueblos originarios en Argentina y deciden compartir y apoyar esas experiencias de lucha por la que ellos están transitando. ${ }^{23}$ Asimismo, devinieron en un espacio de tensiones de distinto tenor entre indígenas y con no indígenas -tal como se describió en el apartado anterior-.

Ninguno de los sectores que intervienen en estos procesos -como indica Lazzari (2011)- son en sí mismos homogéneos, ni pueden agruparse linealmente cada uno como bloque -agentes estatalescientíficos-indígenas- entre quienes reclaman y quienes son interpelados por el reclamo. Pero además de estos actores, me parece importante detenerse en dimensionar otros sujetos no indígenas recién señalados que son importantes para las comunidades mapuche que reclaman y participan de estos eventos y que no suelen ser incluidos hasta la fecha en los estudios académicos sobre restitución de restos humanos indígenas. Me refiero a la participación

23 Desde ya, el apoyo por parte de agentes externos a las comunidades mapuche no se reduce a quienes participan, pero quienes participan efectivamente apoyan la lucha indígena. de abogados que colaboran en las demandas de las comunidades mapuche, vecinos, antropólogos, periodistas de medios de comunicación y otros sujetos afines con sus luchas. Estos agentes son importantes en la producción de estos eventos, de sus interpretaciones y marcos de discusión así como en su posible difusión. Intervienen alineándose, colaborando y apoyando el reclamo y constituyen un eslabón relevante en la práctica y discursos que acompañan las restituciones y en su transmisión.

Ahora bien, quiénes pueden intervenir, cuándo y cómo se lo puede hacer, es algo que está diferencialmente demarcado en el tiempo de duración del evento. Las restituciones suelen combinar "zonas del decir y compartir público" con otras que denominaré aquí de "intimidad", es decir, reservadas solo para el pueblo indígena reclamante. Mientras algunas ceremonias, reflexiones y momentos de las restituciones son abiertas, otras -espacios-momentos de debate, ciertas ceremonias y/o el lugar de entierro- son reservadas exclusivamente para quienes forman parte del mismo colectivo de pertenencia. Estas "zonas de intimidad" son claves y contienen una dimensión política. Son formas de agenciamiento, regulación de relaciones con los otros -aun con aquellos que se reconocen como aliados a la lucha-y preservación y fortalecimiento de un "nosotros".

\section{A modo de cierre. Rearmar los ojos, reabrir los tiempos, revisar trayectorias, recompo- ner tramas}

Según Veena Das (en Ortega, 2008), los testimonios de las víctimas comprenden tres funciones: nombrar la violencia padecida, hacer y acompañar el duelo y establecer relaciones. Las restituciones, con las imágenes de los cuerpos, las performances y cantos, los silencios y los testimonios de quienes estando vivos los reconocen como sus ancestros han permitido eso y algo más. Son, por un lado, un espacio de construcción de memorias, de circulación y entramado del afecto y la afección, que abrieron el campo para discutir, evocar y narrar la propia historia. También para crear y afianzar vínculos, hacer y acompañar el duelo. Pero además, devinieron instrumento de conocimiento, pues habilitaron la reconceptualización de experiencias, produciendo conciencia sobre 
ocultamientos y vivencias de dolor. Y, finalmente, se constituyeron en un dispositivo de transmisión y enseñanza en el que se fortalecen luchas dándoles un sentido, legitimando denuncias e impugnaciones.

En la medida en que se trata de encuentros vinculados con eventos que tienen una fuerte carga e intensidad emotiva, las restituciones pusieron en primer plano -como se ha destacado- ocultamientos padecidos; recuerdos y pasados silenciados sobre violencias sufridas; tópicos de conocimiento y acción desde los cuales abordar esas violencias; el anudamiento de lazos entre indígenas; heterogeneidades internas a este colectivo; ciertas superposiciones, oposiciones y tensiones frente a discursos y prácticas institucionales estatales y la articulación con otros sujetos no indígenas. Más que una restauración que repone un equilibrio, los relatos y reflexiones emergentes en torno a este proceso entre los miembros mapuche de la Comarca destacan la apertura de un campo de relaciones de fuerza, debates y emociones en tensión e irresuelto. Abre al escrutinio ese cuerpo físico -de Margarita Foyel, Inakayal, su mujer y de otros tantos no identificados- para cerrar su ciclo y dejarlo en guardia mostrando tensiones vividas no solo por un cuerpo individual sino por un cuerpo político colectivo.

Las restituciones son así el comienzo, como señalan Curtoni y Chaparro (2011), más que la finalización de un proceso. El comienzo para saber lo que no se había visto junto a aquello que se vio y que se sabe, de manera de volver ese saber más preciso, reaprenderlo y encarnarlo (Didi-Huberman, 2015). El umbral para rearmar los ojos y lazos con una historia presente, una memoria, una genealogía, una ruptura y una continuidad, un desplazamiento y un despliegue. $\mathrm{Y}$ es que en ese proceso se construyen y/o consolidan alianzas, emergen tensiones y se reanudan oposiciones. El cuerpo muerto da vida a un mundo de sentido que fue enajenado y encubierto, a una historia interrumpida, a un territorio expropiado y reclamado, a una lucha colectiva.

Los eventos de restitución se definieron como hechos históricos que, además de reconstruir memorias, quedarán en la memoria. Asimismo se vivieron como una experiencia dolorosa por las violencias infligidas que evocan y las asimetrías irresueltas que manifiesta el mismo acto de restitución. Los recuerdos y conocimientos puestos en juego en la Comarca sobre estas historias de restituciones ponen en tensión tanto el concepto de "patrimonio" como las políticas vinculadas con la patrimonialización de restos humanos indígenas y los saberes admitidos como legítimos. Las reflexiones derivadas de estas restituciones documentan la colonialidad que hasta la actualidad atraviesa la organización de las relaciones, los saberes, los cuerpos y sujetos, al territorio y al patrimonio.

El proceso de restitución dio lugar a una serie de reflexiones y conocimientos que no estaban hasta ańos relativamente recientes en la mira de muchos miembros de varias de estas comunidades de la Comarca. Los relatos transmitidos sobre las historias de estos cuerpos muertos restituidos apuntaron a mostrar la crueldad con que operaron los procesos de selección, colección y exhibición patrimonial y el conocimiento académico en el caso indígena, vinculándolos a políticas genocidas y formas de sometimiento de estos pueblos. Pero también a cuestionar y revisar modalidades de exhibición y construcción de saberes diferenciados, desigualmente valorados y en conflicto; entre los cuales, el cuestionamiento al mausoleo como continuidad del museo y el machi como figura revestida de conocimiento han sido por demás significativos.

Lejos de obturar, las restituciones habilitaron la visualización de violencias, imposiciones y tensiones inconclusas e incluso su transmisión a generaciones posteriores. Pero especialmente al estar acompańadas de una fuerza poderosa y movilizadora como son las emociones, que permiten encarnar en los propios cuerpos la reflexión crítica de los eventos sucedidos y reconocer como propia esa historia, la demanda por la autonomía y por el territorio arrebatado, contienen un alto potencial en la constitución de subjetividades y luchas por derechos. Cuando se produjo la restitución de Margarita Foyel, algunos mapuche de la Comarca sostuvieron que "desde ahora en más se abre todo un camino de lucha, de compromiso para seguir haciendo la restitución y de nuestros lamgen que están encerrados hace más de un siglo". Es difícil predecir si estas memorias, fuerzas y puntos de encuentro emergentes en forma pública en estos procesos de restitución lograrán mantener continuidad 
y cierto ímpetu en el tiempo. Me atrevo a señalar simplemente que, aun cuando ese ímpetu pueda decaer, tal como observó Lazzari (2008) en el caso de la restitución de Mariano Rosas en la provincia de La Pampa, ${ }^{24}$ la vivencia fuertemente emotiva de estas experiencias, y la llama que encendieron, quedará latente en el recuerdo, pasible de ser nuevamente iluminada.

\section{Referencias citadas}

Ametrano, S. (2005). Los procesos de restitución en el Museo de La Plata. Revista argentina de antropología biológica, 17(2), 1-13.

Ametrano, S. (2015). 20 años después: restitución complementaria del Cacique Inacayal y familiares. Museo Disponible en http://sedici.unlp.edu.ar/bitstream/handle/10915/52084/Documento_completo.pdf?sequence=1

Arenas, P. (2011). Ahora Damiana es Krygi. Restitución de restos a la comunidad aché de Ypetimi. Paraguay. Corpus. Archivos virtuales de la alteridad americana, 1(1). Disponible en http://ppct.caicyt.gov.ar/index.php/corpus/issue/view/30/showToc

Bauman, R. (2006). Actuación. En Serie de Folklore Actuación (Performance) (pp. 3-23). Buenos Aires: FFyL-UBA.

Brow, J. (2000). Notas sobre comunidad, hegemonía y los usos del pasado. En Ficha de cátedra de Etnolingüística. El habla en interacción: La comunidad (pp. 21-32). Buenos Aires: FFyL-UBA. (1990, in: Anthropological Quarterly, 63, 1).

Butler, J. (2006). Vida precaria. El poder del duelo y la violencia. Buenos Aires: Paidós.

Carsten, J. (2007). Introduction: Ghosts of Memory. En Carsten, J. Ghosts of Memory. Essays on Remembrance and Relatednes (pp. 1-35). Australia: Blackwell.

Caviglia, S. (2012). Por la restitución completa de los restos de Inakayal, miembros de su familia y de su comunidad. Modalidad Educación Intercultural y Bilingüe (EIB). Chubut: Ministerio de Educación provincia del Chubut.

24 En la restitución de Mariano Rosas, Lazzari observa un "agotamiento y la detención de un ímpetu que la demanda de reconocimiento habría activado y que la respuesta a dicha demanda habría desvirtuado” (2008).
Crespo, C. (2005). "Qué pertenece a quién": Procesos de patrimonialización y Pueblos Originarios en Patagonia. Cuadernos de antropología social, 21, 133-149.

Crespo, C. (2008). Politicas de la memoria, procesos de patrimonialización de los recursos arqueológicos y construcción identitaria entre los Mapuches de la Rinconada de Nahuelpán en Rio Negro. Tesis Doctoral en Ciencias Antropológicas, Facultad de Filosofía y Letras, Universidad de Buenos Aires. Mimeo.

Crespo, C. (2011). Patrimonio arqueológico, memoria y territorio. Procesos de autoctonización entre los mapuches de Lago Puelo, Chubut (Patagonia Argentina). Revista Frontera Norte, 23(45), 231-255.

Crespo, C. (2012). Espacios de "autenticidad", "autoctonía” y "expropiación": el lugar del "patrimonio arqueológico" en narrativas mapuches en El Bolsón, Patagonia Argentina. Cuadernos Interculturales, 10(18), 31-61.

Curtoni, R. y Chaparro, M. G. (2007). El re-entierro del Cacique José Gregorio Yancamil. Patrimonio, política y memoria de piedra en La Pampa Argentina. Revista de Antropología, 19, 9-36.

Curtoni, R. P. y Chaparro, M. G. (2011). Políticas de reparación: Reclamación y reentierro de restos indígenas. El caso de Gregorio Yancamil. Corpus. Archivos virtuales de la alteridad americana, 1(1). Disponible en http://ppct. caicyt.gov.ar/index.php/corpus/issue/view/30/showToc

Das, V. (2008). Trauma y testimonio; El acto de presenciar, Violencia, conocimiento envenenado y subjetividad; Lenguaje y Cuerpo. Transacciones del dolor; La antropología del dolor. En Ortega, F. (Ed.). Veena Das. Sujetos de Dolor, agentes de dignidad (pp. 145-170; 217-250; 343 374; 409-436). Bogotá: Colección Lectura CES.

Didi-Huberman, G. (2015). Remontajes del tiempo padecido. El ojo de la historia 2. Buenos Aires: Biblos.

Di Fini, M. (2001). Visibilidad/Invisibilidad en la relación Sociedad aborigen/Estado Nacional. En Garreta, M. y Bellelli, C. (Comps.). La Trama Cultural. Textos de antropología y arqueología (pp. 208-218). Buenos Aires: Ediciones Caligraf.

Endere, M. L. (2011). Cacique Inacayal. La primer restitución de restos humanos ordenada por ley. Corpus. Archi- 
vos virtuales de la alteridad americana, 1(1). Disponible en http://ppct.caicyt.gov.ar/index.php/corpus/issue/view/30/ showToc

GUIAS (2010). Antropología del genocidio. Identificación y restitución: "colecciones" de restos humanos en el Museo de la Plata. Buenos Aires: De la Campana.

Jimeno, M. (2007). Lenguaje, subjetividad y experiencias de violencia. Antipoda, 5, 169-190.

Jofre, I. K. (2012). Territorios y cuerpos en disputa: reclamos por la restitución y respeto de los cuerpos de nuestros ancestros. En Actas del VI Encuentro de Investigadores en Ciencias Sociales. Democracia y Desarrollo en América Latina. Debates y desafios del siglo XXI. San Juan: Universidad Nacional de San Juan. Edición en CD.

Lazzari, A. (2008). La restitución de los restos de Mariano Rosas: identificación fetichista en torno a la política de reconocimiento de los ranqueles. Estudios en antropología social, 1(1), 35-64.

Lazzari, A. (2011). Reclamos, restituciones y repatriaciones de restos humanos indígenas: cuerpos muertos, identidades, cosmologías, políticas y justicia. Corpus. Archivos virtuales de la alteridad americana, 1(1). Disponible en http://ppct. caicyt.gov.ar/index.php/corpus/issue/view/30/showToc

Mc Cole, J. (1993). Walter Benjamin and the Antinomies of Tradition. Ithaca \& London: Cornell University Press.

Miotti, L. (1994). Inakayal. Un largo camino a Tecka. Boletín de la Secretaria de Extensión Universitaria Facultad de Ciencias Naturales y Museo. Universidad Nacional de La Plata, 2-8.

Oldani, K., Suárez Añón, M. y Pepe, F. M. (2011). Las muertes invisibilizadas del Museo de La Plata. Corpus. Archivos virtuales de la alteridad americana, 1(1). Disponible en http://ppct.caicyt.gov.ar/index.php/corpus/ issue/view/30/showToc

Ortega, F. (Ed.). (2008). Veena Das: Sujetos de Dolor, agentes de dignidad. Bogotá: Colección Lectura CES.
Ortega Martínez, F. (2011). El trauma social como campo de estudios. En Ortega, F. (Comp.). Trauma, cultura $e$ historia: reflexiones interdisciplinarias para el nuevo milenio (pp. 17-61). Bogotá: Colección Lectura CES.

Podgorny, I. (2000). El argentino despertar de las Faunas y de las Gentes Prehistóricas. Coleccionistas, estudiosos, museos y universidad en la creación del patrimonio paleontológico y arqueológico nacional (1875-1913). Buenos Aires: Eudeba.

Podgorny, I. y Politis, G. (1990). ¿Qué sucedió en la historia? Los esqueletos araucanos del Museo de La Plata y la Conquista del Desierto. Arqueología Contemporánea, 3, 73-79.

Politis, G. (1994). El regreso de Inakayal. Museo, 1(3), 46-48.

Pollak, M. (2006). Memoria, Olvido, Silencio. La producción social de identidades frente a situaciones limite. La Plata: Ediciones Al Margen.

Ramos, A. M. (2010). Los pliegues del linaje. Memorias y politicas mapuches-tehuelches en contextos de desplazamientos. Buenos Aires: Eudeba.

Rodríguez, M. E. (2011). "Casualidades" y "causalidades" de los procesos de patrimonialización en la provincia de Santa Cruz. Corpus. Archivos virtuales de la alteridad americana, 1(1). Disponible en http://ppct.caicyt.gov.ar/ index.php/corpus/issue/view/30/showToc

Stella, V. (2016). Las rogativas mapuches como líderes políticos de la memoria. En Ramos, A., Crespo, C. y Tozzini, M. A. (Comps.). Memorias en lucha. Recuerdos y silencios en contextos de subordinación y alteridad. Río Negro: Editorial Universidad de Río Negro, Colección Aperturas.

Stoler, A. L. (2008). Imperial debris: reflections on ruins and ruination. Cultural anthropology, 23(2), 191-219.

Vich, V. y Zavala, V. (2004). Oralidad y Poder. Herramientas metodológicas. Bogotá: Norma. 